\title{
Continuity of Medication Management: Is Transition a Barrier?
}

\section{Nimmi Athuraliya*}

Clinical academic/Staff specialist, Clinical Pharmacology and General Medicine, University of Newcastle, Australia

What is continuity of care in a health care system? It could be defined as ensuring continuum of care during transition from different care settings in a health system. There is an abundance of literature to indicate that transition is a potential threat to continuum of health care. Health related issues during patient movement from one health setting to another present multiple challenges for patients, care givers and health care providers. In an era where health care is heavily dependent on pharmaceuticals, more often than not the health issues during transition health issues are related to discrepancies in medications. The most vulnerable patients to 'care transition related health problems' are those with chronic diseases on multiple complex drug regimes [1]. Discrepancies in medication lists of these patients are attributed to; errors in medication documentation [2-4], poor communication between health care providers [5,6] and medication non - adherence by patients [7].

Medication discrepancies could be intentional, addressing the current medical needs of the patient or, unintentional due to documentation errors. A substantial proportion of hospital prescribing errors were attributed to unintentional documentation errors in medication histories on admission to hospitals [8]. At the point of hospitalization in the Emergency department (ED) many health professionals participate in the care of patients. It is not incorrect to state that the main focus at the ED is triage which identifies and manage acute life threatening conditions. Admission medication lists are secondary in a list of priorities of patient management in a busy ED. Most often information on medication history is obtained from the patient who may not be in a state to give an accurate account of the list. Such information if not verified could result in continuation of the error with potential unwarranted patient harm.

Similar documentation errors can occur on discharge and can potentially cause medication related harm [5] when the patient moves to the community resulting in a possible re-hospitalization. In contrast to the scenario on admission to the hospital, at the point of discharge to the community, the responsibility of preparing the discharge summaries lies with the most junior doctor of a medical team and most often the process is not supervised. A high medication error rate (28 potentially serious adverse events/200 patients) was observed in discharge summaries in an acute hospital setting in New Zealand [9]. Bedell et al. [10] reported that 51\% and $29 \%$ of the discrepancies of patient medication lists in an out patients setting were due to non-documentation of the current medications and a recorded medication not in current use respectively. Further, re-prescription of ceased medications was noted in another study indicating poor communication between health care providers resulting in significant health care implications [8].

Additionally, patient non-adherence is a significant health problem that contributes to the burden of medication related harm. Patient compliance to medications could vary depending on the type and severity of disease, quality and quantity of medications and ability to understand instructions [7,11]. Countries with trends in increasing populations of elderly and culturally and linguistically diverse people are faced with potential proportionate growth of medication nonadherence and related health consequences. The scenario is complicated by availability of different dosage forms of same medication in public sector and private sector pharmacies leading to patient confusion during transition of care. The different dosage forms could be different in colour, shape and size (spironolactone and Spiractin). As such it is possible that the actual list of drugs the patient takes to be different to the prescribed medication list. The potential consequent would be either non-adherence and therapeutic failures or over dose of medications.

All the evidence indicates that transition to hospital care could be a potential 'threat' for patient's health, especially for those on complex multiple medication regimens. Number of measures has been used to minimize medication related patient harm during transition. Electronic prescribing, pharmacists led medication reconciliation, patient counselling and telephone follow-up were some strategies used [12-14]. Of note is an emerging recognition of the importance of Medication Reconciliation. It is a process of obtaining an accurate medication history, identifying discrepancies if any and taking appropriate action to resolve the issues in the context of care plan throughout the transition of care [15].

Medication reconciliation is an important step forward to prevent different levels of unintentional medication related errors occurring throughout hospital stay. In a multidisciplinary health care team the clinical pharmacists will be the most qualified and suitable member to lead medication reconciliation processes in hospitals. The Australian Pharmaceutical Advisory Council Guiding Principles to achieve continuity in medication management, highlights the pathway of medication management continuum in both hospital and in community setting [16]. A review on pharmacists resource in Australian public hospitals indicates shortage of clinical pharmacists to carry out all the principles laid down in the guidelines [17]. The same scenario may exist in most countries with worse situations in developing countries. As such it is unlikely that the expected level of medication reconciliation takes place in most hospital settings.

It must be emphasized, even though medication reconciliation is an improvement towards quality medication management, if the process is used only to reduce discrepancies in medication lists during transition, there will not be an incentive to improve the medication plan when the patient's health trajectory is off course. It is prudent to use the opportunity of transition to hospital setting to re-evaluate the medications based on patients changing health needs.

Continuity of care and medication reconciliation should also include medications available in patients' residence. Complementary medicines, 'left-over' medicines from past purchases could be confusing to patients especially in situations when there are differences in appearances of the dosage form/branded products of same

*Corresponding author: Nimmi Athuraliya, Clinical Academic/Staff Specialist, Clinical Pharmacology and General Medicine, University of Newcastle, Australia E-mail: Nimmi.Athuraliya@newcastle.edu.au

Received May 17, 2012; Accepted May 19, 2012; Published May 21, 2012

Citation: Athuraliya N (2012) Continuity of Medication Management: Is Transition a Barrier? Primary Health Care 2:e105. doi:10.4172/2167-1079.1000e105

Copyright: (c) 2012 Athuraliya N. This is an open-access article distributed under the terms of the Creative Commons Attribution License, which permits unrestricted use, distribution, and reproduction in any medium, provided the original author and source are credited. 
Citation: Athuraliya N (2012) Continuity of Medication Management: Is Transition a Barrier? Primary Health Care 2:e105. doi:10.4172/2167$1079.1000 \mathrm{e} 105$

chemica entity. The interphase between discharges from hospital and community visit to the General Practitioner is a potentially vulnerable period for patients.

Transition of health care is potentially hazardous to vulnerable patients given the fact that shortage of a monitoring system through Clinical Pharmacist resource in hospital settings. What are the responsibilities of clinicians as care providers to a patient in transition? Medical undergraduate training in Universities focus on medication reviews as part of the core curriculum in Clinical Pharmacology. As such medication review should be a responsibility of the medical team and an essential component of the care plan for patients who have changed health needs. This process will be efficiently implemented if the care providers have immediate access to patent's electronic health records. Accessibility of patient records to both community and hospital health care providers would establish an effective communication system between the two care sites.

Last but not the least, 'From Hospital to Home health care' programmes where a nurse or a pharmacist visits the patient's residence was known to reduce potential medication related harm [18]. Implementation of such programmes requires selection of vulnerable patients who will benefit from the process, identifying trained staff within a limited resources pool and efficient coordination.

The complexities of health care systems and prescription medication management will continue to challenge health care providers. Health care systems must strive to find solutions to eliminate medication related harm. It is important that decisions are taken at executive level in health care systems to provide the basic requirements for effective management of patients particularly between the community and hospital care settings. Additionally, medical teams in both hospital and community care settings cannot ignore the fact that patients expect to receive comprehensive care that includes medication management. It is a responsibility that the medical teams need to bear and they must ensure continuity of medications to reduce harm in transition.

\section{References}

1. Bell CM, Brener SS, Gunraj N, Huo C, Bierman AS, et al. (2011) Association of ICU or hospital admission with unintentional discontinuation of medications for chronic diseases. JAMA 306: 840-847.

2. Callen J, Mclntosh J, Li J (2010) Accuracy of medication documentation in hospital discharge summaries: A retrospective analysis of medication transcription errors in manual and electronic discharge summaries. Int $\mathrm{J}$ Med Inform 79: 58-64
3. Frei P, Huber LC, Simon RW, Bonani M, Lüscher TF (2009) Insufficient medication documentation at hospital admission of cardiac patients: a challenge for medication reconciliation. J Cardiovasc Pharmacol 54: 497-501.

4. Hartel MJ, Staub LP, Röder C, Eggli S (2011) High incidence of medication documentation errors in a Swiss university hospital due to the handwritten prescription process. BMC Health Serv Res 11: 199.

5. Boockvar KS, Liu S, Goldstein N, Nebeker J, Siu A, et al. (2009) Prescribing discrepancies likely to cause adverse drug events after patient transfer. Qual Saf Health Care 18: 32-36

6. Hallas J, Harvald B, Gram LF, Grodum E, Brøsen K, et al. (1990) Drug related hospital admissions: the role of definitions and intensity of data collection, and the possibility of prevention. $\mathrm{J}$ Intern Med 228: 83-90.

7. Neugaard BI, Priest JL, Burch SP, Cantrell CR, Foulis PR (2011) Quality of care for veterans with chronic diseases: performance on quality indicators, medication use and adherence, and health care utilization. Popul Health Manag 14: 99-106.

8. van der Linden CM, Kerskes MC, Bijl AM, Maas HA, Egberts AC, et al. (2006) Represcription after adverse drug reaction in the elderly: a descriptive study. Arch Intern Med 166: 1666-1667.

9. McMillan TE, Allan W, Black PN (2006) Accuracy of information on medicines in hospital discharge summaries. Intern Med J 36: 221-225

10. Bedell SE, Jabbour S, Goldberg R, Glaser H, Gobble S, et al. (2000) Discrepancies in the use of medications: their extent and predictors in an outpatient practice. Arch Intern Med 160: 2129-2134.

11. Karliner LS, Auerbach A, Nápoles A, Schillinger D, Nickleach D, et al. (2012) Language barriers and understanding of hospital discharge instructions. Med Care 50: 283-289.

12. Walsh KE, Landrigan CP, Adams WG, Vinci RJ, Chessare JB, et al. (2008) Effect of computer order entry on prevention of serious medication errors in hospitalized children. Pediatrics 121: e421-e427.

13. Marotti SB, Kerridge RK, Grimer MD (2011) A randomised controlled trial of pharmacist medication histories and supplementary prescribing on medication errors in postoperative medications. Anaesth Intensive Care 39: 1064-1070.

14. Schnipper JL, Kirwin JL, Cotugno MC, Wahlstrom SA, Brown BA, et al (2006) Role of pharmacist counseling in preventing adverse drug events after hospitalization. Arch Intern Med 166: 565-571.

15. SHPA Practice Standards (2007) SHPA standards of practice for the provision of medication reconciliation. J Pharm Pract Res 37: 231-233.

16. Australian Pharmaceutical Advisory Council (2005) Guiding principles to achieve continuity in medication management. Commonwealth of Australia Canberra.

17. O'Leary KM, Allinson YM (2006) Pharmaceutical review: Resource implications for the pharmacy component in Australian public hospitals. Journal of Pharmacy Practice and Research 36: 291-96.

18. Bruning K, Selder F (2011) From hospital to home healthcare: the need for medication reconciliation. Home Healthc Nurse 29: 81-90. 